\title{
Estimation of Rice Growth Using RADARSTA-2 SAR Images at Seosan Region
}

\author{
Yihyun Kim, Sukyoung Hong*, Kyoungdo Lee, and Soyeong Jang \\ Soil and Fertilizer Division, National Academy of Agricultural Science, RDA, Suwon 441-707, Korea \\ (Received: June 28 2013, Accepted: July 30 2013)
}

\begin{abstract}
Radar remote sensing is appropriate for monitoring rice because the areas where this crop is cultivated are often cloudy and rainy. Especially, Synthetic Aperture Radar (SAR) can acquire remote sensing information with a high temporal resolution in tropical and subtropical regions due to its all-weather capability. This paper analyzes the relationships between backscattering coefficients of rice measured by RADARSAT-2 SAR and growth parameters during a rice growth period. We examined the temporal variations of backscattering coefficients with full polarization. Backscattering coefficients for all polarizations increased until Day Of Year (DOY 222) and then decreased along with Leaf Area Index (LAI), fresh weight, and Vegetation Water Content (VWC). Vertical transmit and Vertical receive polarization (VV)-polarization backscattering coefficients were higher than Horizontal transmit and Horizontal receive polarization (HH)-polarization backscattering coefficients in early rice growth stage and HH-polarization backscattering coefficients were higher than VV-polarization backscattering coefficients after effective tillering stage (DOY 186). Correlation analysis between backscattering coefficients and rice growth parameters revealed that $\mathrm{HH}$-polarization was highly correlated with LAI, fresh weight, and VWC. Based on the observed relationships between backscattering coefficients and variables of cultivation, prediction equations were developed using the HH-polarization backscattering coefficients.
\end{abstract}

Key words: Synthetic aperture radar, Rice, Backscattering coefficients, Growth parameters

Comelation analysis between backscattering coefficients and variables of rice cultivation revealed that HH-polarization is highly comelated with LAI, fresh weight, and VWC.

\begin{tabular}{|c|c|c|c|c|c|c|}
\hline \multirow[b]{2}{*}{ Growth data } & \multicolumn{3}{|c|}{ A-area } & \multicolumn{3}{|c|}{ B-area } \\
\hline & $\mathrm{HH}$ & $\mathrm{VV}$ & $\mathrm{HV}$ & $\mathrm{HH}$ & $\mathrm{VV}$ & $\mathrm{HV}$ \\
\hline LAI & $0.97 * * *$ & $0.93^{* * *}$ & $0.92 * * *$ & $0.98 * * *$ & $0.93 * * *$ & $0.89^{* * *}$ \\
\hline Fresh weight $\left(\mathrm{kg} 10 \mathrm{a}^{-1}\right)$ & $0.96^{* * *}$ & $0.91 * * *$ & $0.91 * * *$ & $0.94 * * *$ & $0.89 * * *$ & $0.86^{* *}$ \\
\hline Dry weight $\left(\mathrm{kg} 10 \mathrm{a}^{-1}\right)$ & $0.93^{* * *}$ & $0.87^{* *}$ & $0.86^{* *}$ & $0.89^{* * *}$ & $0.84^{* *}$ & $0.83 * *$ \\
\hline $\begin{array}{l}\text { Vegetation water } \\
\text { content }\left(\mathrm{kg} 10 \mathrm{a}^{-1}\right)\end{array}$ & $0.97 * * *$ & $0.92 * * *$ & 0.90 *** & $0.95^{* * *}$ & $0.90 * * *$ & $0.87^{* *}$ \\
\hline
\end{tabular}

** and ***: Significant at the $0.05,0.01$ probability levels, respectively.

NS : not significant at the 0.05 level.

*Corresponding author : Phone: +82312900344, Fax:+82312900282, E-mail: syhong67@korea.kr

${ }^{\S}$ Acknowledgement: This work was supported by a grant from the Agenda Program (PJ007753032013), Rural Development Administration, Republic of Korea. 


\section{Introduction}

농업 분야에서는 작물의 종류와 성장에 따른 레이더 자 료의 후방산란 특성 및 변화를 살펴보고, 이를 경작지 면적 을 추출하거나 작황예측에 활용하는 기술이 연구되고 있다. 레이더에서 얻어지는 후방 산란 (backscattering)은 작물의 종류, 생체량, 엽면적지수, 수분 함량, 배열과 분포에 따라 달라진다. 특히 다편파 레이더 자료를 이용하면 표면 산란 (surface scattering), 이중 산란 (double bounce scattering) 및 체적 산란 (volume scattering)의 정도를 구분하여 작물 의 특성을 구별하는데 용이하다.

합성구경레이더 (SAR; Synthetic Aperture Radar)는 능 동형 시스템 (active system)으로 에너지원이 인공발생 극 초단파 (microwave)로 자체적으로 펄스신호를 내보내어 대 상체 (target)로부터 되돌아오는 신호인 후방산란계수 (backscattering coefficients)를 얻는 것으로 날씨에 영향을 거의 받지 않는다. 특히 농업분야에서 레이더 기술의 장점 을 살려 수확량 예측, 작물의 생육 모니터링, 관개답 면적 추정, 재해 피해 모니터링 등에 활용할 수 있다.

레이더자료를 농업에 적용하는데 있어 작물에 따른 후방 산란계수 특성을 파악하는 것이 매우 중요하다. 작물 생육 을 관측하는 과정에서 후방산란계수는 작물의 생육변화패 턴, 작물의 군락 구조, 지표면 거칠기, 토양수분, 시스템의 안테나 주파수, 입사각, 편파 등 여러 요소들에 영향을 받으 며, 산란 특성과 밴드 주파수에 따른 침투력 차이를 이해하 는 것도 중요하다. 레이더의 다중편파 특성을 이용하면 단 일편파에 비해 많은 정보를 얻을 수 있는 이점이 있다. 최근 합성구경레이더 (Synthetic Aperture Radar, SAR) 위성영 상을 이용한 작물 분류 기술의 개발이나 미래 위성개발의 수요를 제안하는데 기여할 수 있도록 작물별로 편파 조합에 따른 산란 특성 정보를 파악하는 연구가 필요하다.

다중편파를 이용하여 농경지를 매핑하고 모니터링 하는 것은 수직으로 위치하는 작물에 대한 Horizontal transmit and Horizontal receive polarization (HH) 와 Vertical transmit and Vertical receive polarization (VV) 신호의 감쇠 (attenuation)가 다른 것을 이용하는 기술이다. 1980년 후반 부터 레이더 및 항공기 영상을 이용하여 작물생육과의 관계 를 분석하고 평가하는 연구가 진행되기 시작하였다. Le Toan et al. (1989)은 X-밴드 SAR 영상 (HH-, $\mathrm{VV}$-편파)을 이용하여 벼 재배지역을 생육기간동안 모니터링하고 후방 산란계수 변화를 분석하였다. 벼 생육초기에서는 $\mathrm{VV}$-편파 가 $\mathrm{HH}$-편파보다 후방산란계수가 높게 나타났고 벼 군락이 형성되면서 $\mathrm{HH}$-편파가 더 높게 나타난 것으로 보고하였다.

Le Toan et al. (1997)은 European remote sensing satellite (ERS-1) 영상을 이용하여 벼 생육시기별 후방산 란계수와 벼 생체중과의 관계를 분석하여 추정식을 구하
였다. Kurosu et al. (1997)은 벼 생육기간 중 ERS-1 SAR 영상에서 얻어진 후방산란계수의 노이즈를 감쇄하는 방 법을 찾고 Landsat TM 자료와 함께 이용하여 농경지를 분류하였다. Chakraborty et al. (2005)은 인도 West Bengal 벼 재배지역의 생육기간 동안 RADARSAT-1 영상을 이용 하여 입사각도 (S1: 21-27도, S5: 39-42도, S6: 42-49, S7: 45-49) 별로 후방산란계수를 산출하고 벼 생육인자 와의 상관성을 알아보았다. 벼 생육시기에 따른 초장과 후방산란계수 관계는 이차다항식이 성립되었다. 입사각 40 도 이상인 경우 (shallow angle data)는 입사각 23도 보 다 초장과의 상관성이 높았다.

Chen et al. (2007)은 Environment Satellite (ENVISAT) Advanced SAR (ASAR) 영상을 이용하여 벼 생육초기에 $\mathrm{HH}, \mathrm{VV}$-편파 영상을 수집하고 초장, 생체중과 상관성을 분석하였다. 또한, $\mathrm{ASAR} \mathrm{HH}-, \mathrm{VV}$-편파 후방산란계수를 결합하여 벼 초장, 생체중 지도를 작성하였다. Bouvet et al. (2009)은 ENVISAT 영상자료를 통해 메콩강 지역의 작 부체계를 분류하였고, ENVISAT ASAR wide-swath 영상자 료를 이용하여 메콩강 지역에 대해 시계열별 벼 재배 지도 를 작성하였다 (Bouvet and Le Toan, 2011).

국내의 경우 Hong et al. (2000)은 벼 생육기간 동안 9시 기의 RADARSAT-1 영상을 이용하여 벼 생육을 모니터링한 결과, 후방산란계수를 이용하여 초장, 엽면적지수, 생체중, 건물중을 추정할 수 있었다. 하지만 RADARSAT-1 영상은 단일편파로 다양한 산란특성정보를 얻는데 한계점이 있다.

본 논문에서는 다중편파 RADARSAT-2 영상을 이용하여 벼 생육변화를 모니터링하고 영상에서 추출한 편파별 후방 산란계수와 벼 생육인자들과의 상관성 분석을 통해 서산지 역의 벼 생육을 추정하고자 하였다.

\section{Materials and Methods}

연구지역 서산연구지역 $\mathrm{A}$ 포장 $\left(36^{\circ} 57^{\prime} 34.90^{\prime \prime} \mathrm{N}\right.$, $\left.126^{\circ} 28^{\prime} 28.77^{\prime \prime} \mathrm{E}\right), \mathrm{B}$ 포장 $\left(36^{\circ} 57^{\prime} 59.66^{\prime \prime} \mathrm{N}, 126^{\circ} 28^{\prime}\right.$ $\left.16.03^{\prime \prime} \mathrm{E}\right)$ 에서 벼를 대상으로 연구를 수행하였다. A 포장 벼 품종은 주남벼, 재식밀도는 $30 \mathrm{~cm} \mathrm{x} 17 \mathrm{~cm}$ 이고 벼 이앙 일은 5월 31일 (Day Of Year, DOY 162), 수확일은 10월 15 일 (DOY 289) 이다. B 포장 벼 품종은 새누리벼, 재식밀도 는 $30 \mathrm{~cm} \mathrm{x} 16 \mathrm{~cm}$ 이고 벼 이앙일은 5월 28일 (DOY 159), 수확일은 10월 15일 (DOY 289) 이다.

벼 생육 조사 및 분석 벼 생육조사는 초장 (plant height), 생체중 (fresh weight), 건물중 (dry weight), 엽면적지수 (leaf area index), 식생 수분함량 (vegetation water content) 등을 생육 기간 동안 정기적으로 조사 하였다 (Fig. 1). 벼 시료 채취 생육을 대표할 수 있는 지점에서 3 주 


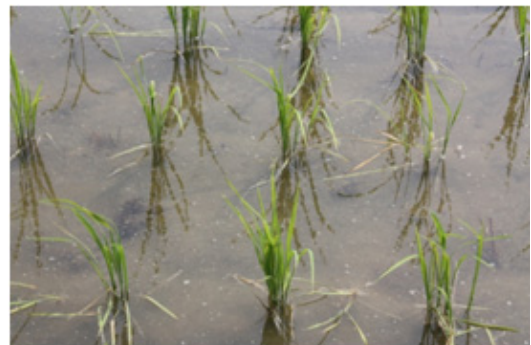

(6.15, DOY 167)

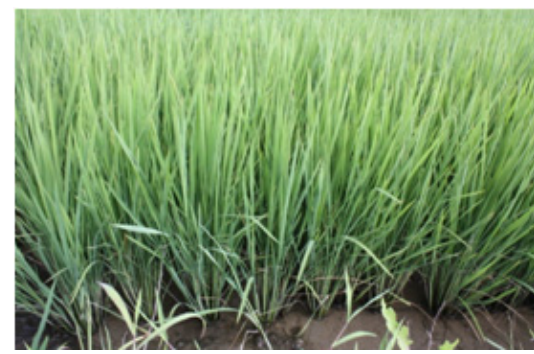

(7.27, DOY 209)

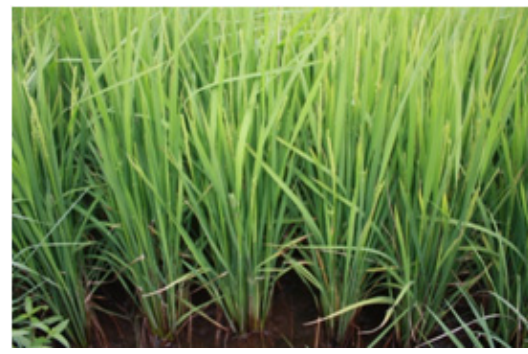

(8.22, DOY 235)

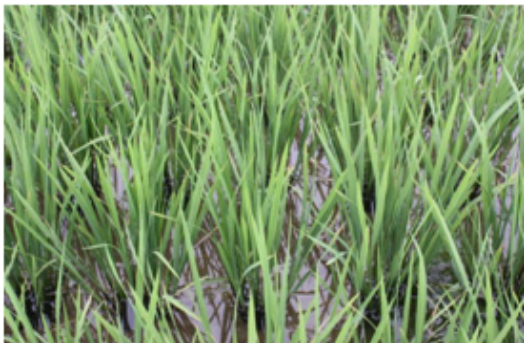

(7.4, DOY 186)

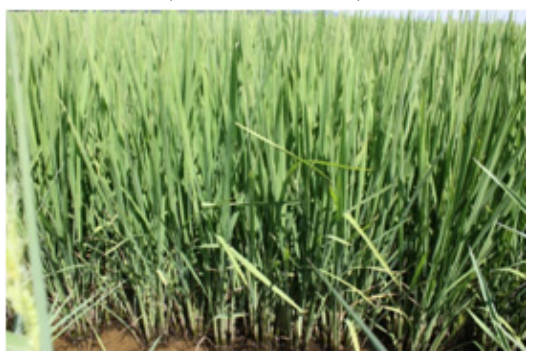

(8.3, DOY 216)

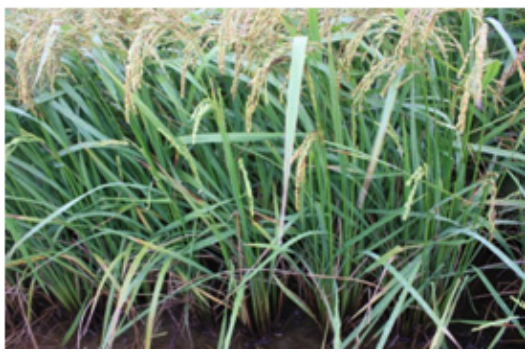

(9.3, DOY 257)

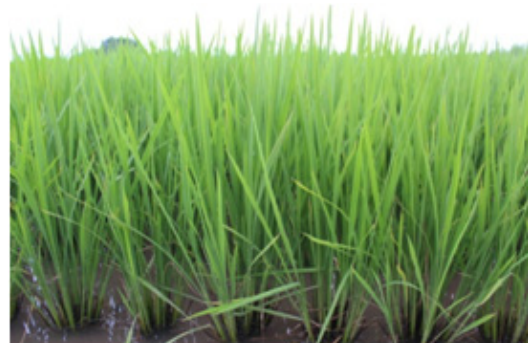

(7.16, DOY 198)

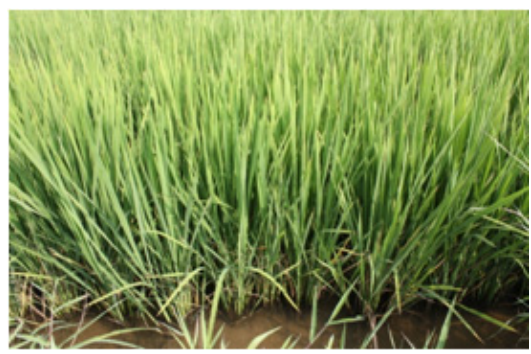

(8.9, DOY 222)

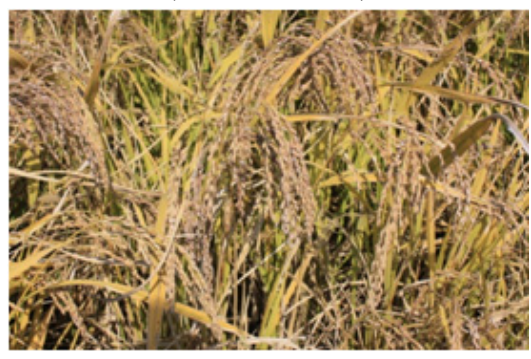

(10.13, DOY 286)

Fig. 1. Field photos rice in various growth stages (A-area).

를 선택하여 초장, 생체중, 엽면적지수를 측정하고 $60^{\circ} \mathrm{C}$ 에 서 36시간 건조 후 건물중을 측정하였다. 엽면적지수는 단 위지표 면적에서 자라고 있는 모든 잎들의 면적의 합을 지 표면적으로 나눈 비율로써 개엽을 모두 떼어내어 LI-3100 (LI-COR, Inc.)을 이용하여 직접 면적을 측정한 후 주(株) 당 재식밀도로 구하였다. 식생 수분함량은 생체중과 건물중 의 차이로 얻었다. SAS (Statistical Analysis System) 프로 그램 (Enterprise Guide ver. 4.2, SAS Institute Inc.)을 이 용하여 상관분석 및 회귀분석을 하였다.

레이더 영상 후방산란계수 산출 사용한 레이더 위 성영상은 RADARSAT-2 영상으로 2007년에 캐나다에서 발 사하였으며 중심주파수 $5.4 \mathrm{GHz}$, 파장 $5.6 \mathrm{~cm}$, 입사각은 $20^{\circ} \sim 59^{\circ}$ 범위이다. 최대 공간 해상도는 약 $1 \mathrm{~m}$ 이며, RADARSAT-1이 HH 편파만을 사용했지만 RADARSAT-2는 단일, 이중, 다중편파 사용이 가능하다 (Table 1). 또한, RADARSAT-1은 단일 방향 영상 획득만 가능하므로 재방문 주기가 긴 단점이 있는 반면 RADARSAT2는 왼쪽/오른쪽 관 측 모드를 적용하여 재방문 주기를 반으로 줄여 운용하고 있다. RADARSAT-2 영상자료 수집 현황은 Table 2 와 같다. 본 연구에 사용한 영상은 Fine Quadpol 모드, 다중편파
$(\mathrm{HH}, \mathrm{VV}, \mathrm{HV}, \mathrm{VH})$ 이며, 공간해상도는 $7.6 \mathrm{~m}$ 로 입사각도가 $42^{\circ}$ 에서 6씬 (scene) 영상자료를 수집하였다 (Table 2, Fig. 2).

다중편파 분석을 위하여 Single Look Complex (SLC) 자 료로 처리하였다. 정량적 통계 분석을 위하여 획득된 자료 는 look-up table을 이용하여 후방산란계수를 추출 하였고, 스펙클 잡음 (speckle noise)을 줄이기 위하여 $5 \times 5$ Lee 필 터를 적용 하였다.

$$
\text { Calibrated value }=\frac{\text { digitalvalue }^{2}+B}{A}
$$

식 (1)에서 A는 range dependent gain list, B는 constant offset을 의미한다. A의 값은 multi look 영상의 parameter 파일에서 calibration gain 값을 사용하며, B의 값은 RADARSAT2 영상에서 제공하는 lutSigma.xml 파일에서의 offset 값을 사용한다. 이때, $\mathrm{A}$ 의 calibration gain 값은 $\mathrm{dB}$ 이므로 후방 산란계수 식은 식 (2)와 같다.

$\sigma_{\mathrm{dB}}^{\circ}=10 * \log 10\left(\right.$ digital value $\left.{ }^{2}+\mathrm{B}\right)-\mathrm{A}$

여기서 $\sigma_{\mathrm{dB}}^{\circ}$ 은 $\mathrm{HH}, \mathrm{VV}, \mathrm{HV}$ 값의 후방산란계수를 말한다. 
Table 1. System parameters of RADARSAT-2 satellite.

\begin{tabular}{|c|c|c|}
\hline Specification & & RADARSAT-2 \\
\hline Nation & & Canada \\
\hline Type/application & & Earth Observing (Radar) \\
\hline Equipment & & C-band synthetic aperture radar (SAR) \\
\hline Launch date & & December, 14, 2007 \\
\hline Frequency & & $5.4 \mathrm{GHz}$ \\
\hline Wave length & & $5.6 \mathrm{~cm}$ \\
\hline Incident angle & & $20^{\circ} \sim 49^{\circ}$ \\
\hline Band width & & $100 \mathrm{MHz}$ \\
\hline Altitude & & $798 \mathrm{~km}$ \\
\hline Polarization & & $\mathrm{HH}, \mathrm{VV}, \mathrm{HV}, \mathrm{VH}, \mathrm{HH} / \mathrm{VV}, \mathrm{HH} / \mathrm{HV}, \mathrm{VV} / \mathrm{HV}$ \\
\hline \multirow{8}{*}{$\begin{array}{l}\text { Resolution } \\
\text { (Polarization options) }\end{array}$} & Spotlight & $1.6 \mathrm{~m} \times 0.8 \mathrm{~m}(\mathrm{HH}$ or $\mathrm{VV}$ or $\mathrm{HV}$ or $\mathrm{VH})$ \\
\hline & Ultra-Fine & $1.6 \mathrm{~m} \times 2.8 \mathrm{~m}(\mathrm{HH}$ or $\mathrm{VV}$ or $\mathrm{HV}$ or $\mathrm{VH})$ \\
\hline & Multi-Look Fine & $3.1 \mathrm{~m} \times 4.6 \mathrm{~m}(\mathrm{HH}$ or $\mathrm{VV}$ or $\mathrm{HV}$ or $\mathrm{VH})$ \\
\hline & Fine & $5.2 \mathrm{~m} \times 7.7 \mathrm{~m}(\mathrm{HH}$ or $\mathrm{VV}$ or $\mathrm{HV}$ or $\mathrm{VH}$ or $\mathrm{HH}+\mathrm{HV}$ or $\mathrm{VV}+\mathrm{VH})$ \\
\hline & Standard & $9.0 \mathrm{~m} \times 7.7 \mathrm{~m}(\mathrm{HH}$ or $\mathrm{VV}$ or $\mathrm{HV}$ or $\mathrm{VH}$ or $\mathrm{HH}+\mathrm{HV}$ or $\mathrm{VV}+\mathrm{VH})$ \\
\hline & ScanSAR wide & $72 \mathrm{~m} \times 100 \mathrm{~m}(\mathrm{HH}$ or $\mathrm{VV}$ or $\mathrm{HV}$ or $\mathrm{VH}$ or $\mathrm{HH}+\mathrm{HV}$ or $\mathrm{VV}+\mathrm{VH})$ \\
\hline & Fine Quad-Pol & $5.2 \mathrm{~m} \times 7.6 \mathrm{~m}(\mathrm{HH}+\mathrm{VV}+\mathrm{HV}+\mathrm{VH})$ \\
\hline & Standard Quad-Pol & $9.0 \mathrm{~m} \times 7.6 \mathrm{~m}(\mathrm{HH}+\mathrm{VV}+\mathrm{HV}+\mathrm{VH})$ \\
\hline
\end{tabular}

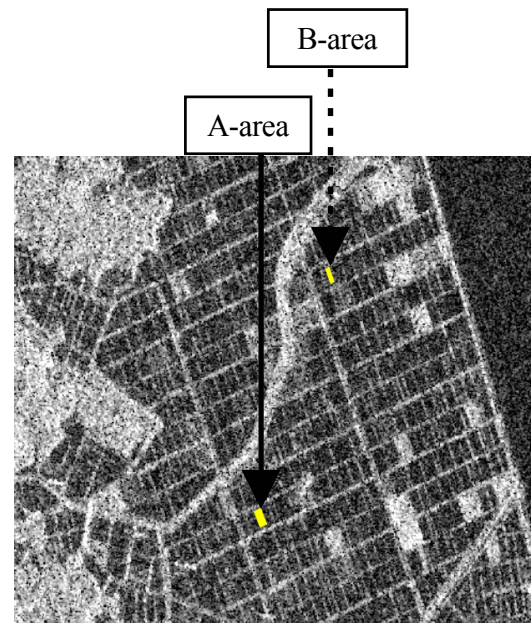

(5.23, DOY 144)

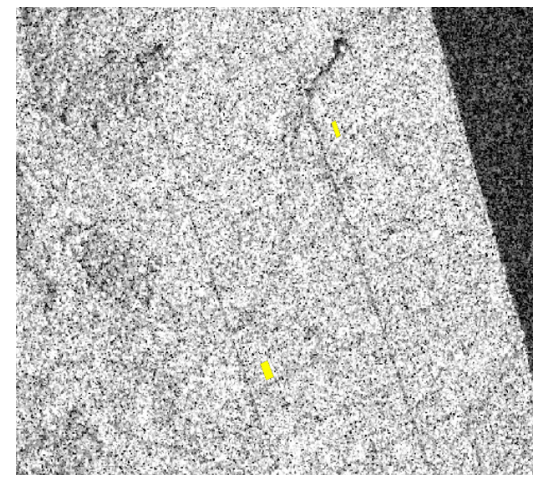

(8.3, DOY 222)

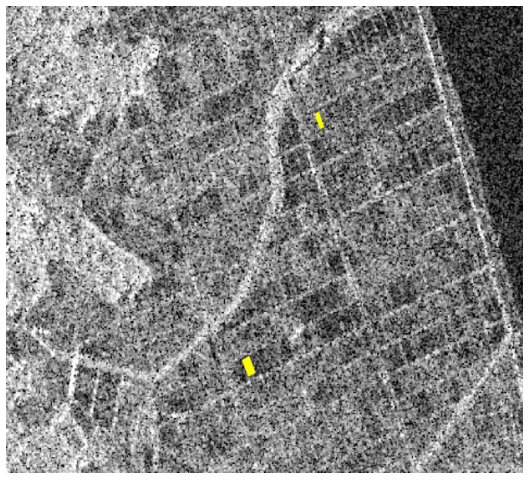

(6.16, DOY 168)

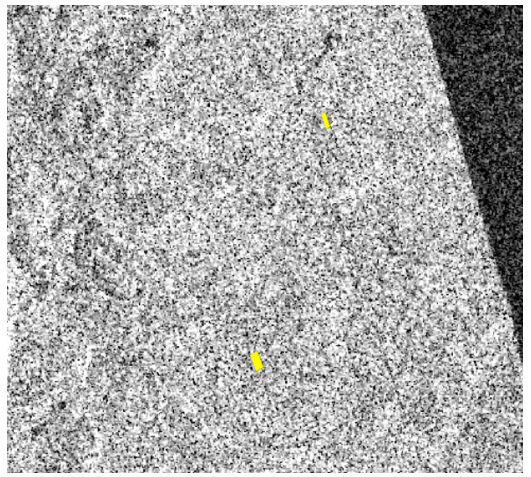

(8.22, DOY 235)

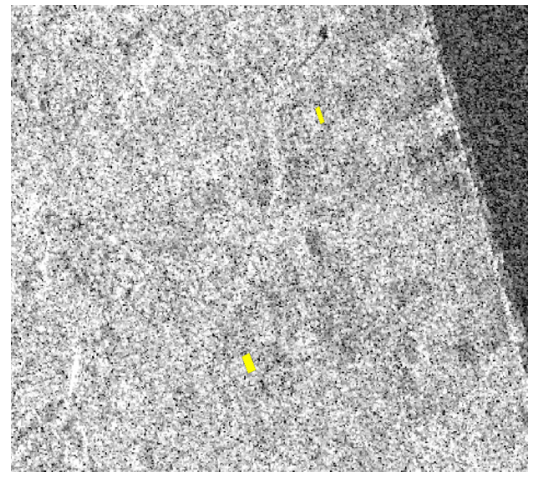

(7.3, DOY 216)

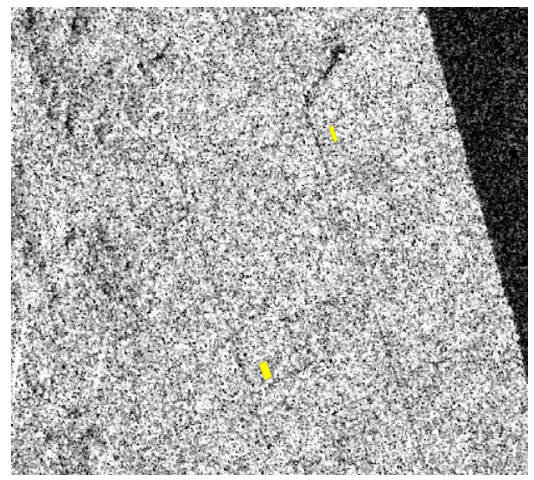

(9.13, DOY 257)

Fig. 2. The images of RADARSAT-2 SAR from satellite at subjected area in 2012 according to time series. 
Table 2. Dataset in RADARSAT-2 satellite.

\begin{tabular}{lc}
\hline \hline Specification & RADARSAT-2 \\
\hline Mode & Fine Quad-pol \\
Resolution & $7.6 \mathrm{~m}$ \\
Polarization & $\mathrm{HH}, \mathrm{VV}, \mathrm{HV}, \mathrm{VH}$ \\
Incident angle & $42^{\circ}$ \\
Pass & Descending \\
Swath width & $25 \mathrm{~km} \mathrm{x} 25 \mathrm{~km}$ \\
Shooting time & $6: 33$ \\
Acquisition date & $5 / 23,6 / 16,7 / 4,8 / 3,8 / 22,9 / 13$ \\
\hline
\end{tabular}

\section{Results and Discussion}

\section{생육시기별 레이더 후방산란계수와 벼 생육 변화}

RADARSAT-2 영상에서 얻어진 후방산란계수와 벼 생육 조사 자료를 비교 분석하였다. 벼 생육시기에 따른 생육인 자들의 변화를 관측한 결과 엽면적지수의 경우 $\mathrm{A}, \mathrm{B}$ 연구포 장 모두에서 이앙기 이후 계속 증가하다가 8월 9일 (DOY 222) 이후 감소하였고, 생체중, 식생수분함량은 8월 22일 (DOY 235)에서 최대값을 보인 후 수확기까지 감소하는 경 향을 보였다 (Fig. 3).

RADARSAT-2 영상 후방산란계수 범위는 각각 $-30.6 \mathrm{~dB}$ $\sim-6.0 \mathrm{~dB}$ (A 연구포장), $-29.3 \mathrm{~dB} \sim-8.4 \mathrm{~dB}$ (B 연구포 장) 이었다. $\mathrm{HH}$-편파 후방산란계수가 다른 편파 ( $\mathrm{VV}-$ 편 파, $\mathrm{HV}$-편파)들에 비해 높게 나타났다. 두 연구지역에서 영상 편파별 후방산란계수가 생육시기에 따라 증가하다가 8 월 9일 (DOY 222) 이후 감소하였다. 벼 생육초기에는 VV편파가 $\mathrm{HH}-, \mathrm{HV}-$ 편파보다 후방산란계수가 높게 나타났지 만 유효분얼기인 7월 4일 (DOY 186) 이후 $\mathrm{HH}$-편파가 다른 편파들에 비해 후방산란계수가 높게 나타났다. 이 결과는 Kim et al. (2012)이 발표한 결과와 일치한다. Kim et al. (2012)은 지상 레이더 산란계 (L, C, X-밴드 안테나)를 이 용하여 벼 생육을 모니터링 하였는데 C-밴드 안테나 $\mathrm{HH}-$ 편파 후방산란계수는 벼 생육초기 (이앙 후 25 일 경)에는 $\mathrm{VV}$-편파 보다 낮게 나타났지만 유효분얼기 (DOY 166, 6월 16 일) 이후에는 VV-편파 후방산란계수보다 높게 나타났고 그 경향은 벼 수확기까지 계속 진행되었다. A 연구포장 생 체중, 엽면적지수가 B 연구포장보다 높게 나타났는데 영상 후방산란계수도 동일한 결과가 나타났다 (Fig. 3).

RADARSAT-2 영상은 재 방문주기가 12 일로 연속적으로 작물생육변화를 모니터링 하기가 힘들다. 따라서 2009년

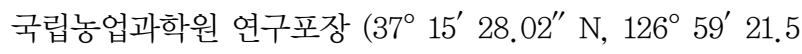
$\left.2^{\prime \prime} \mathrm{E}\right)$ 에서 지상 레이더 산란계를 이용하여 벼 생육을 모니 터링 한 실험 결과와 비교하여 레이더 영상의 후방산란계수 변화 결과를 비교해보았다 (Fig. 4). 지상 레이더 산란계 C밴드 안테나 규격은 레이더 영상 안테나 규격과 일치하며

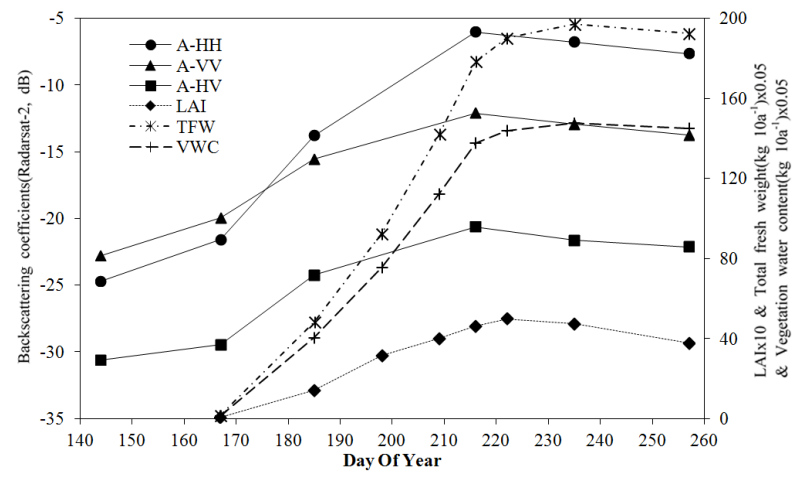

(a)

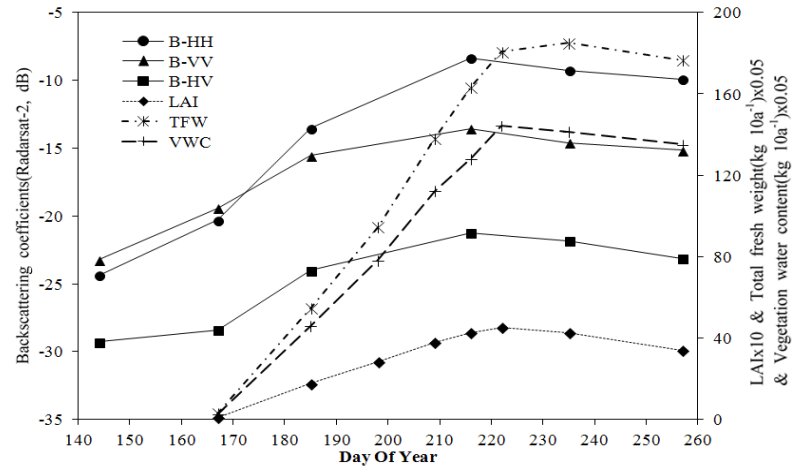

(b)

Fig. 3. Temporal variations of backscattering coefficients for RADARSAT-2 satellite and rice growth parameters; (a) A area, and (b) B area.

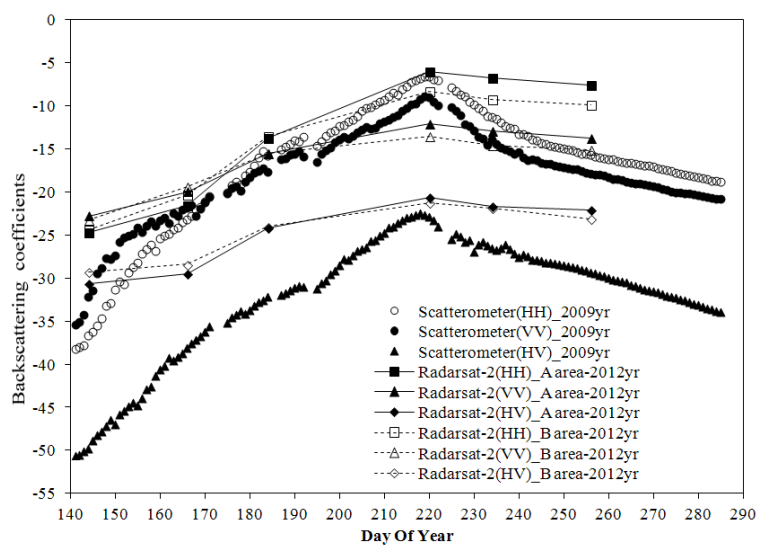

Fig. 4. Temporal variations of backscattering coefficients for RADARSAT-2 (2012) and backscattering coefficients for ground-based scatterometer (2009).

10 분단위로 측정함으로써 레이더영상의 시간해상도를 보완 해 줄 수 있다 (Kim et al., 2012).

지상 레이더 산란계 후방산란계수는 모든 편파에서 8월 8일 (DOY 220)에 후방산란계수가 가장 높았고 그 이후 감 소하였는데 레이더 영상 후방산란계수에서도 동일한 경향 을 보였다. 또한 두 시스템 (레이더 영상, 지상 레이더 산란 계)에서 벼 생육초기에는 $\mathrm{VV}$-편파가 다른 편파들에 비해 후방산란계수가 높게 나타났지만 군락이 형성된 이후에는 
Table 3. Correlation coefficients for the relationship between backscattering coefficients and growth parameters over study period.

\begin{tabular}{|c|c|c|c|c|c|c|}
\hline \multirow[b]{2}{*}{ Growth data } & \multicolumn{3}{|c|}{ A-area } & \multicolumn{3}{|c|}{ B-area } \\
\hline & $\mathrm{HH}$ & VV & HV & $\mathrm{HH}$ & VV & HV \\
\hline LAI & $0.97 * * *$ & $0.93 * * *$ & $0.92 * * *$ & $0.98 * * *$ & $0.93^{* * *}$ & $0.89^{* * *}$ \\
\hline Fresh weight $\left(\mathrm{kg} 10 \mathrm{a}^{-1}\right)$ & $0.96^{* * *}$ & $0.91^{* * *}$ & $0.91^{* * *}$ & $0.94 * * *$ & $0.89^{* * *}$ & $0.86^{* *}$ \\
\hline Dry weight $\left(\mathrm{kg} 10 \mathrm{a}^{-1}\right)$ & $0.93^{* * *}$ & $0.87 * *$ & $0.86^{* *}$ & $0.89 * * *$ & $0.84 * *$ & $0.83^{* *}$ \\
\hline Vegetation water content $\left(\mathrm{kg} 10 \mathrm{a}^{-1}\right)$ & $0.97 * * *$ & $0.92 * * *$ & $0.90^{* * *}$ & $0.95 * * *$ & $0.90^{* * *}$ & $0.87 * *$ \\
\hline
\end{tabular}

** and $* * *$ : Significant at the $0.05,0.01$ probability levels, respectively.

NS : not significant at the 0.05 level.

$\mathrm{HH}$-편파가 후방산란계수 중 가장 높게 나타났다. 시간해상 도가 뛰어난 지상 레이더 산란계 후방산란계수 변화와의 비 교를 통해 RADARSAT-2 영상을 이용하여 생육시기에 따른 후방산란계수 변화를 감지 (detect) 할 수 있음을 확인하였다.

\section{레이더 영상 후방산란계수를 이용한 벼 생육 추정}

생육시기별 RADARSAT-2 영상 후방산란계수와 벼 생육 인자 변화 분석 결과를 바탕으로 후방산란계수와 엽면적지 수, 생체중, 건물중, 식생수분함량 과의 상관관계를 분석하 였다 (Table 3). 엽면적지수는 $\mathrm{HH}$-편파 후방산란계수와 A, $\mathrm{B}$ 연구포장 모두에서 상관계수가 가장 높게 나타났고 $(\mathrm{r}=0.97$, $\mathrm{r}=0.98)$, 다른 편파들에서도 상관성이 높게 나타났다 $(\mathrm{r} \geq$ 0.89). 생체중과 편파별 후방산란계수와의 관계를 알아 본 결 과 $\mathrm{HH}$-편파에서 상관계수가 가장 높게 나타났다 $(\mathrm{r}=0.96$, $\mathrm{r}=0.94) . \mathrm{HH}$-편파에서 건물중과의 상관계수가 높았고 $(\mathrm{r}=0.93, \mathrm{r}=0.89)$, 다른 편파에서도 상관성을 보였다 $(\mathrm{r} \geq$ $0.83)$.

식생 수분함량은 가뭄을 평가하거나 수확량을 예측할 때 중요한 입력변수로 사용되고, 마이크로파 자료로부터 토양 수분을 추정하는데 매우 중요한 인자값이다 (Jackson and Schmugge, 1991; Gao and Goetz, 1995, Yilamz et al., 2008). 식생 수분함량은 $\mathrm{HH}$-편파 후방산란계수와 상관성 이 가장 높게 나타났고 $(\mathrm{r}=0.97, \mathrm{r}=0.95), \mathrm{VV}$-편파, $\mathrm{HV}$-편 파 후방산란계수 순으로 상관성이 높았다. 지상 레이더 산 란계에서 얻어진 후방산란계수와 벼 생육인자와의 상관성 을 분석한 결과에서도 $\mathrm{HH}$-편파가 다른 편파들에 비해 생육 인자들과 상관계수가 더 높게 나타났다 (Kim et al., 2009, Kim et al., 2012). HH-편파는 다른 편파들에 비해 수직 구 조물에 더 민감하게 반응한 반면 $\mathrm{HV}$-편파는 반응도가 낮게 나타났다. 이 결과로 볼 때 $\mathrm{HH}$-편파가 다른 편파들에 비해 군락에 좀 더 효과적으로 침투하고 생육시기별로 산란특성 분석에 좀 더 효과적인 것으로 판단된다.

편파별 후방산란계수와 벼 생육인자와의 상관분석에서 상관계수가 가장 높은 $\mathrm{HH}$-편파 후방산란계수를 이용하여 벼 생육인자들을 추정하였다. A, B 연구포장의 생육인자들 과 후방산란계수를 합한 후 벼 출수기 전, 후로 구분하여 생

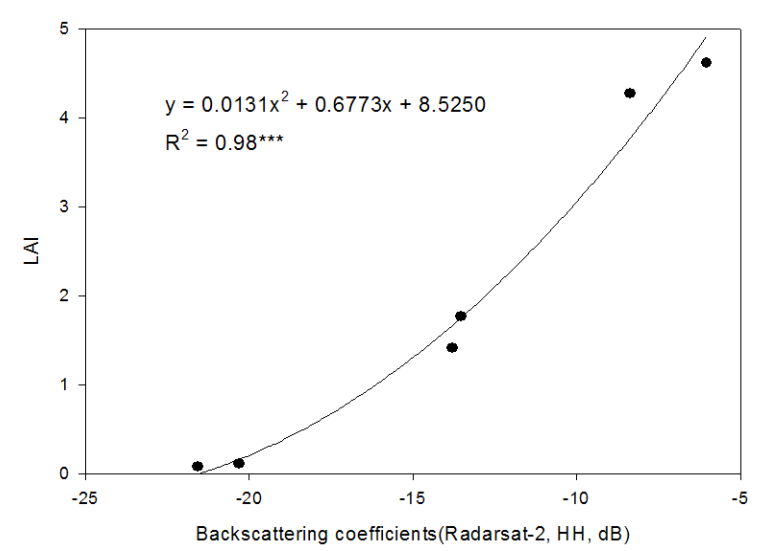

(a)

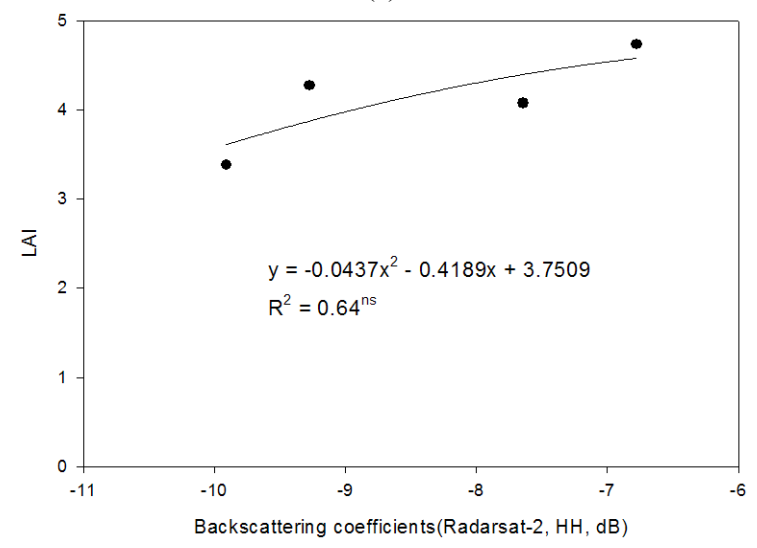

(b)

Fig. 5. Relationship between backscattering coefficients in RADARSAT-2 (HH-polarization) and LAI; (a) before heading stage, and (b) after heading stage.

육추정을 위한 회귀식을 작성하였다. 엽면적지수와 $\mathrm{HH}-$ 편 파 후방산란계수와의 관계에서 벼 출수기 전에는 결정계수 가 0.98 이었고, 출수기 이후에는 결정계수가 0.64 로 나타 났다 (Fig. 5). 벼 출수기이후 두 변수간의 결정계수가 낮은 이유는 엽면적지수는 생체중, 식생수분함량에 비해 감소폭 이 크게 나타나 후방산란계수가 엽면적지수의 변화를 감지 하기가 어려운 것으로 판단된다. Fig. 6. 은 $\mathrm{HH}$-편파 후방 산란계수를 이용한 벼 생체중 추정 결과를 보여주고 있는데 두 변수간에는 이차식 관계가 성립되었고 벼 출수기 전, 후 모두 결정계수가 각각 높게 나타났다 $\left(\mathrm{R}^{2}=0.98, \mathrm{R}^{2}=0.97\right)$. 


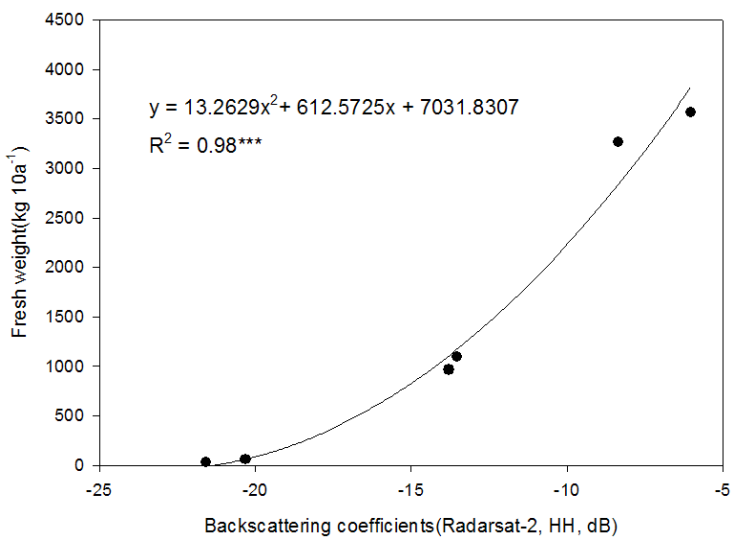

(a)

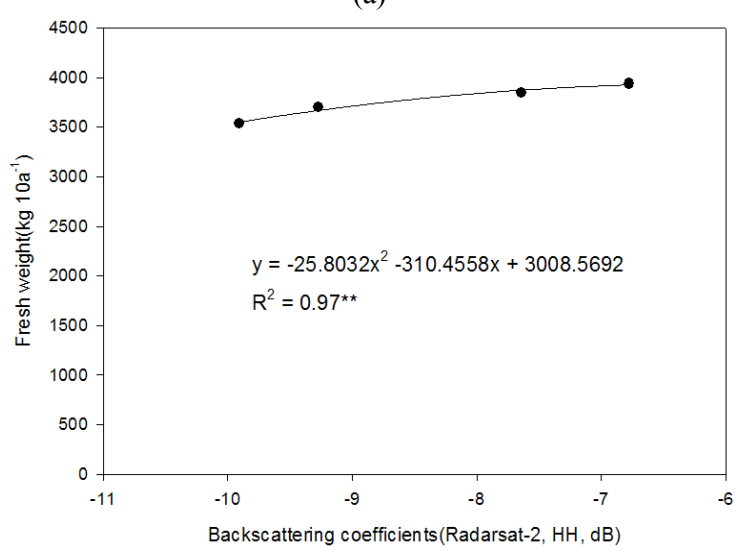

(b)

Fig. 6. Relationship between backscattering coefficients in RADARSAT-2 (HH-polarization) and fresh weight; (a) before heading stage, and (b) after heading stage.

$\mathrm{HH}$-편파 후방산란계수를 이용하여 벼 식생수분함량을 추 정한 결과 벼 출수기 전 후 모두 결정계수가 높게 나타났고 $\left(\mathrm{R}^{2} \geq 0.95\right)$, 식생 수분함량 $95 \%$ 이상을 설명할 수 있었다 (Fig. 7). $\mathrm{HH}$-편파 후방산란계수를 이용하는 것이 벼 엽면 적지수, 생체중, 건물중, 식생 수분함량을 각각 가장 높게 추정할 수 있었음을 확인하였다.

\section{Conclusions}

본 연구에서는 벼 생육시기에 따른 RADARSAT-2 영상 후방산란계수와 벼 생육인자들과의 관계분석을 통해 두 변 수들간의 상관관계를 분석하고 후방산란계수를 이용하여 벼 생육을 추정하였다. 벼 생육초기에는 $\mathrm{VV}$-편파가 다른 편파 들에 비해 후방산란계수가 높게 나타났지만 유효분얼기 이 후 (7월 4일, DOY 186) 이후 $\mathrm{HH}$-편파 후방산란계수가 가장 높게 나타났다. 편파별 후방산란계수와 벼 생육인자들과의 상관성을 분석한 결과 $\mathrm{HH}$-편파 후방산란계수가 엽면적지 수 $(r=0.97, r=0.98)$, 생체중 $(r=0.96, r=0.94)$, 건물중 $(r=0.93, r=0.89)$, 식생 수분함량 $(r=0.97, r=0.95)$ 모든 생 육인자들과 상관계수가 가장 높게 나타났다. $\mathrm{HH}$-편파 후방

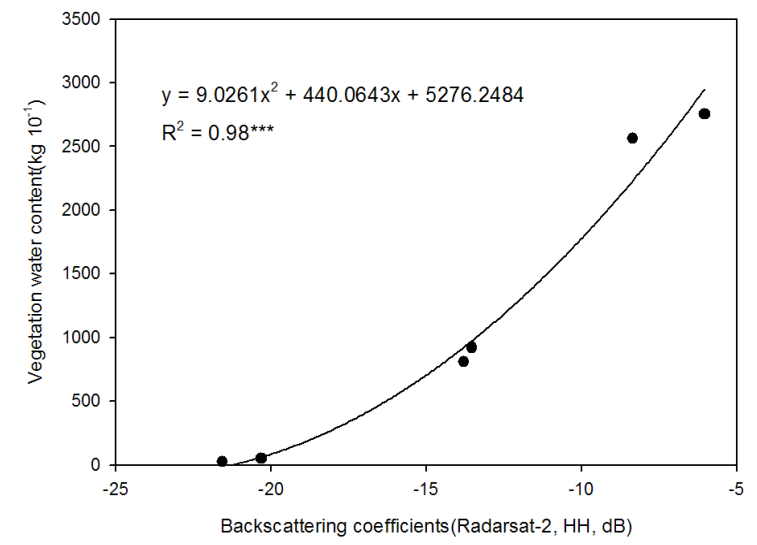

(a)

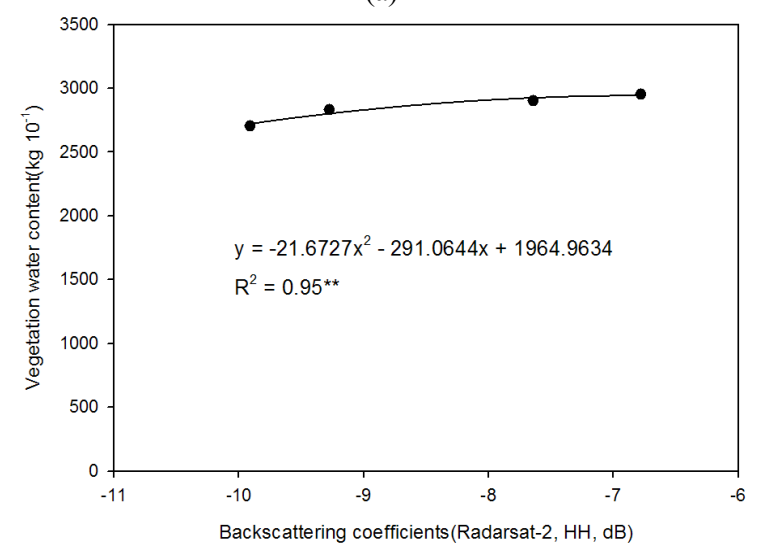

(b)

Fig. 7. Relationship between backscattering coefficients in RADARSAT-2 (HH-polarization) and vegetation water content; (a) before heading stage, and (b) after heading stage.

산란계수를 이용하여 벼 생육인자를 추정한 결과 벼 출수기 전이 출수기 이후보다 결정계수가 높게 나타났고 모든 생육 인자 변이의 $95 \%$ 이상을 설명할 수 있었다. 따라서 이들 결 과들을 통해 RADARSAT-2 영상을 이용하여 벼 생육 추정 가능성을 확인하였다.

\section{Acknowledgments}

This work was supported by a grant from the Agenda Program (PJ007753032013), Rural Development Administration, Republic of Korea.

\section{References}

Bouvet, A., T. Le Toan, and N. Lamdao. 2009. Monitoring of the rice cropping system in the Mekong Delta using ENVISAT/ASAR dual polarization data. IEEE Trans. Geosci. Remote Sens. 47:517-526.

Bouvet, A. and T. Le Toan. 2011. Use of ENVISAT/ASAR wide-swath data for timely rice fields mapping in the Mekong River Delta. Remote Sens. Environ. 115(4):1090-1101. 
Chakraborty, M., K.R. Manjunath, S. Panigrahy, N. Kundu, and J.S. Parihar. 2005. Rice crop parameter retrieval using multi-temporal, multi-incidence angle Radarsat SAR data. ISPRS J Photogramm Remote Sens. 59(5): 310-322.

Chen, J., H. Lin, and Z. Pei. 2007. Application of ENVISAT ASAR data in mapping rice crop growth in Southern China. IEEE Geosci. Remote Sens. Lett. 4:431-435.

Gao, B.C. and A.F.H. Goetz. 1995. Retrieval of equivalent water thickness and information related to biochemical components of vegetation canopies from AVIRIS data. Remote Sens. Environ. 52:155-162.

Hong, S.Y., S.H. Hong, and S.K. Rim. 2000. Relationship between Radarsat backscattering coefficient and rice growth. Korean J. Remote Sens. 16(2):109-116.

Jackson, T.J. and T.J. Schmugge. 1991. Vegetation effects on the passive microwave emission of soils. Remote Sens. Environ. 36:203-212.

Kim, Y.H., S.Y. Hong, and H.Y. Lee. 2009. Estimation of paddy rice growth parameters using L, C, X-bands polarimetric scatterometer. Korean J. Remote Sens. 25:31-44.
Kim, Y.H., T.J. Jackson, R. Bindlish, H.Y. Lee, and S.Y. Hong. 2012. Radar vegetation index for estimating the vegetation water content of rice and soybean. IEEE Geosci. Remote Sens. Lett. 9(4):564-568.

Kurosu, T., M. Fujita, and K. Chiba. 1997. The identification of rice fields using multi-temporal ERS-1 C-band SAR data. Int. J. Remote Sens. 18(2):953-965.

Le Toan, T., H. Laur, E. Mougin, and A. Lopes. 1989. Multitemporal and dual-polarization observations of agricultural vegetation covers by X-band SAR images. IEEE Trans. Geosci. Remote Sens. 27(6):709-718.

Le Toan, T., F. Ribbes, L.F. Wang, N. Floury, K.H. Ding, J.A. Kong, M. Fujita, and T. Kurosu. 1997. Rice crop mapping and monitoring using ERS-1 data based on experiment and modeling results. IEEE Trans. Geosci. Remote Sens. 35:41-56.

Yilmaz, M.T., E.R. Hunt, L.D. Goins, S.L. Ustin, V.C. Vandrbilt, and T.J. Jackson. 2008. Vegetation water content during SMEX04 from ground data and Landsat 5 Thematic Mapper imagery. Remote Sens. Environ. 112:350-362. 